\title{
The nursing position after operation and the work of breathing
}

\author{
R OBERT MAR SHALL \\ From the Nuffield Department of Surgery, The Radcliffe Infirmary, Oxford
}

\begin{abstract}
Patients after operation are often nursed with the foot of the bed raised in order to facilitate drainage of blood from the legs and of secretions from the trachea. Measurements of the changes in lung volume, of the oxygen cost of breathing, and of the movements of the rib cage and abdomen in the sitting, supine, and 15 degree head-down positions have been made in three subjects. The subjects selected were one overweight, one of medium, and one of lean body build. The oxygen cost of breathing was considerably increased in the head-down position in the overweight subject, less so in the one of medium build, and not at all in the lean subject. The cause of the increased oxygen cost of breathing and of its influence on the position in which patients are nursed after operation is discussed.
\end{abstract}

In 1900 Fowler advocated that patients with diffuse septic peritonitis should be nursed with the head and trunk elevated. Fowler realized the danger of thrombosis occurring as a result of stasis of blood in the legs, but the reduction in mortality brought about by this position was great enough to outweigh the increased danger of venous thrombosis and pulmonary embolism.

Since its introduction, Fowler's position has been overused and misused, often being adopted in all patients undergoing abdominal surgery irrespective of septic complications. The high incidence of post-operative leg vein thrombosis and pulmonary embolism has been blamed on the stasis which Fowler's position induces, and in recent years there has been a tendency to nurse patients with the foot of the bed raised during the immediate post-operative period. Fifteen degrees is usually considered the optimal angle of tilt, for at this angle blood drains from the legs towards the heart and the trachea drains towards the larynx (Fig. 1). A 15 degree head-down position is not often achieved in the ward because this necessitates raising the foot of the bed by about $50 \mathrm{~cm}$. and the patient tends to slide along the bed unless the shoulders are supported. A compromise is usually reached by raising the foot of the bed by about $23 \mathrm{~cm}$. (9 degrees). Most $\stackrel{\mathbb{Q}}{\mathscr{Q}}$ patients find this position comfortable but some, $\overrightarrow{\vec{O}}$ particularly those who are obese, find breathing $\frac{3}{3}$ difficult.

This study was carried out to investigate the work and efficiency of breathing in the 15 degree head-down position as compared with the horizontal-supine and sitting positions. The effect of $\underset{\times}{\stackrel{\nu}{\nu}}$ body build was of particular interest and three $\dot{\sigma}$ subjects of widely varying types were chosen to 3 . illustrate the influence of obesity and physical $ᄋ$ fitness.

\section{METHODS}

The measurements were made on three subjects. Onen was an overweight, unfit male, one a male of medium. body build, and one a thin, athletic female subject. 0 Their physical characteristics are shown in Table I.N
FIG. 1. Diagram to illustrate the angle of the trachea and the course of drainage of blood from the lower limb when a subject is in the 15 degree head-down position

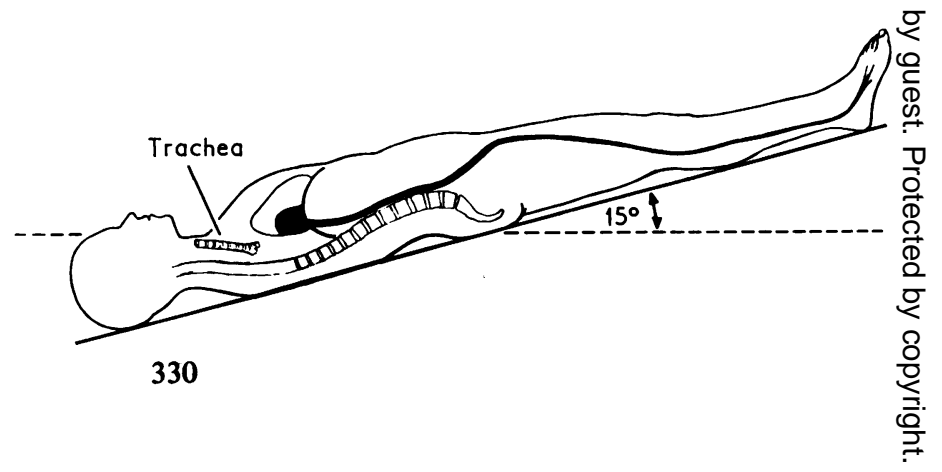


T A B L E I

PHYSICAL CHARACTERISTICS OF THE SUBJECTS

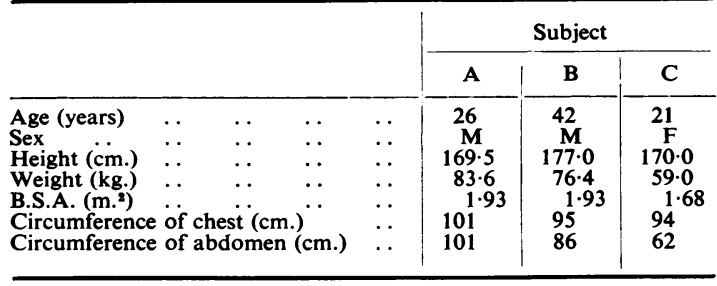

POSTURE Measurements were made with the subject sitting in a chair or lying supine on a tilting bed in the horizontal or 15 degree head-down positions. Boards were placed under the mattress to try to standardize the 15 degree position, which would have been a slightly smaller angle for the obese subject if the mattress had sagged. Shoulder rests were provided in the 15 degree head-down position, but the pressure against these was only slight. In some of the experiments with pneumographs the patient was supported by strapping the ankles to the foot of the bed.

LUNG VOLUMES These were measured on a closedcircuit spirometer system and the functional residual capacity was measured by the helium dilution technique.

OXYGEN COST OF BREATHING This was measured by the method described by Campbell, Westlake, and Cherniak (1959), using the closed-circuit spirometer system with lengths of $2.5 \mathrm{~cm}$. bore rubber tube to increase the dead space. Measurements of oxygen uptake were made for periods of 20 minutes with each of the added dead spaces of 700 and $1,300 \mathrm{ml}$. Initial and final measurements were made with no added dead space.

EFFICIENCY OF BREATHING This was measured in subject $B$ only, in the sitting and 15 degree headdown positions. The method used was that described by Campbell et al. (1959) using water seal resistance against inspiration. In order to increase the energy expended against the resistance all measurements were made with an added dead space of $700 \mathrm{ml}$. Calculations of the efficiency of breathing were made on the assumption that the work equivalent of $1 \mathrm{ml}$. of oxygen was $2 \cdot 1 \mathrm{~kg} . \mathrm{m}$.

MEChANiCAl PROPERTIES OF LUNGS AND CHEST WALl The non-elastic resistance of the lungs was measured by the use of intra-oesophageal pressure measurements, a pneumotachygraph, and the subtraction method of Mead and Whittenberger (1953). Measurements of relaxation pressure were made with the subject connected to a spirometer, to record changes in volume, and a water-filled manometer connected to one nostril to record pressure changes. The other nostril was blocked.

PNEUMOGRAPH MEASUREMENTS These were made using mercury-in-rubber strain gauges attached to the chest at the level of the nipples and to the abdomen at the level of the umbilicus. Thes outputs from the strain gauges, together with the tidal volume, were recorded on an oscillograph.

\section{RESULTS}

LUNG VOLUMES The effect of posture on the lung volumes of the three subjects is shown in Fig. 2. Subjects $\mathbf{A}$ and $\mathbf{B}$ both showed a considerable

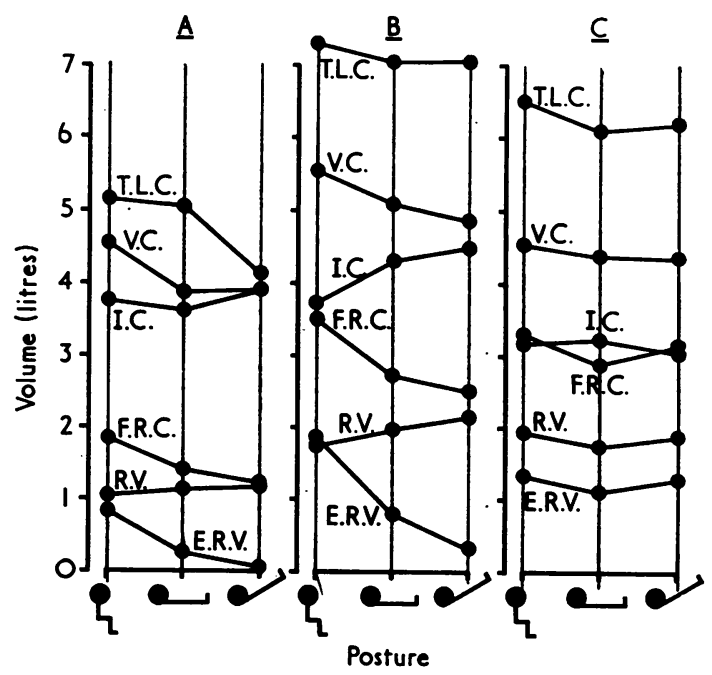

FIG. 2. Changes in lung volume with posture in subjects $A, B$, and $C$.

fall in functional residual capacity in the supine positions as compared with the sitting position, but subject $\mathrm{C}$ showed a much smaller change and there was a small increase in functional residual capacity in the 15 degree head-down position as compared with the horizontal position.

OXYGEN COST OF BREATHING The oxygen cost of the increased ventilation in the three subjects is shown in Fig. 3. Each point is the mean of one to four measurements of oxygen uptake with or without the added dead space. The oxygen cost of breathing was considerably increased in the headdown position in the overweight subject, less so in the one of medium build, and not at all in the lean subject. In subjects $A$ and $B$ the oxygen cost of maintaining an additional ventilation of 10 litres 

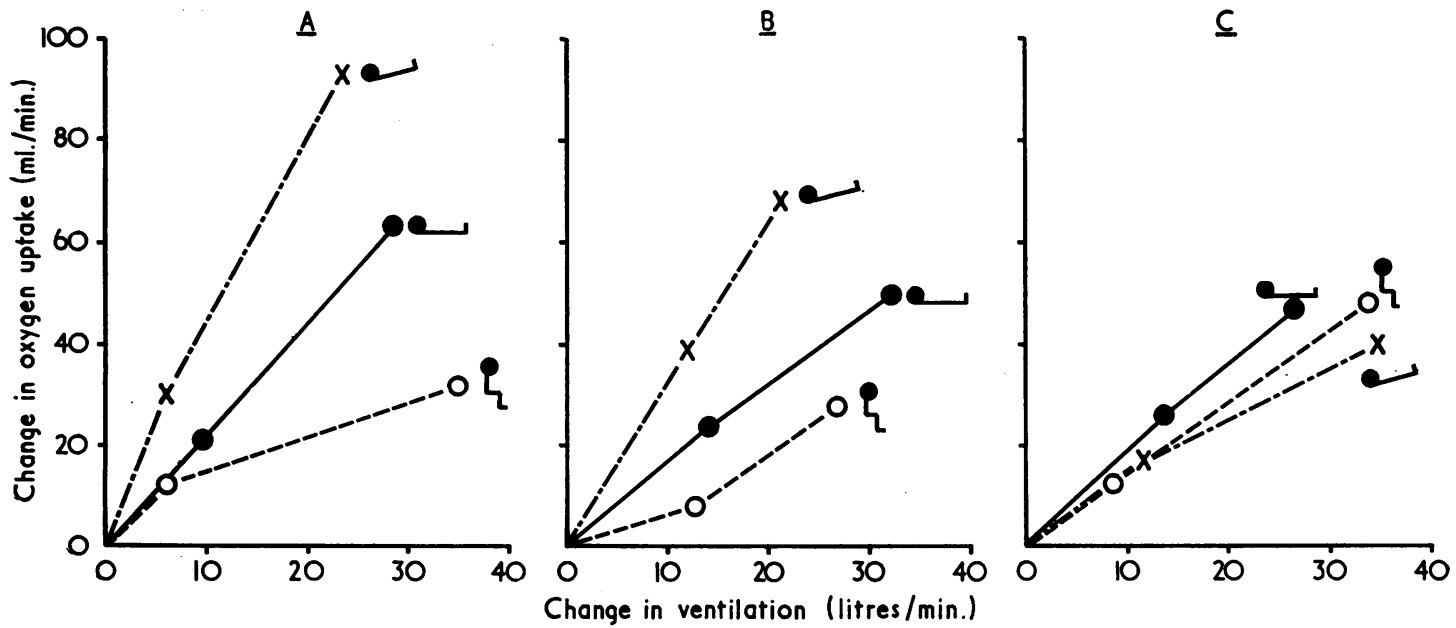

FIG. 3. The oxygen cost of ventilation in subjects $A, B$, and $C$ in the sitting, supine horizontal, and 15 degree head-down positions.

per minute was approximately three times as high when lying 15 degrees head-down as when sitting, and it doubled when the subject was tilted 15 degrees head-down from the horizontal position.

EFFICIENCY OF BREATHING This was measured on subject $B$ in the sitting and 15 degree head-down positions. The results of three estimations are shown in Table II.

\section{T A B L E I I}

SUBJECT B: EFFICIENCY OF BREATHING MEASURED ON THREE OCCASIONS

\begin{tabular}{|c|c|c|c|c|c|c|}
\hline \multicolumn{6}{|c|}{ Posture } & $\begin{array}{c}\text { Efficiency } \\
(\%)\end{array}$ \\
\hline $\begin{array}{l}\text { Sitting } \\
15 \text { degree head-down }\end{array}$ & $\ddot{*}$ & $\ddot{.}$ & $\ddot{x}$ & $\ddot{x}$ & $\ddot{*}$ & $\begin{array}{r}13.6 \\
3.8\end{array}$ \\
\hline $\begin{array}{l}\text { Sitting } \\
15 \text { degree head-down }\end{array}$ & $\cdots$ & $\ddot{x}$ & $\ddot{x}$ & $\ddot{n}$ & $\ddot{n}$ & $\begin{array}{l}7 \cdot 0 \\
2 \cdot 0\end{array}$ \\
\hline $\begin{array}{l}\text { Sitting } \\
\text { is degree head-down }\end{array}$ & $\begin{array}{l}\cdots \\
\cdots\end{array}$ & $\begin{array}{l}\cdots \\
\cdots\end{array}$ & $\begin{array}{l}\cdots \\
\cdots\end{array}$ & $\begin{array}{l}\cdots \\
\cdots\end{array}$ & $\ddot{x}$ & $\begin{array}{l}8 \cdot 8 \\
4 \cdot 5\end{array}$ \\
\hline
\end{tabular}

PNEUMOGRAPH MEASUREMENTS The results are shown in Fig. 4 and Table III. As might be expected, the greatest change in abdominal girth with tilting occurred in the obese subject $A$, and the smallest change in the lean subject $C$. In the two subjects $A$ and $B$, the sitting position produced some restriction of abdominal movement as compared with chest movements but this did not occur in subject $\mathbf{C}$. This subject had a relatively greater

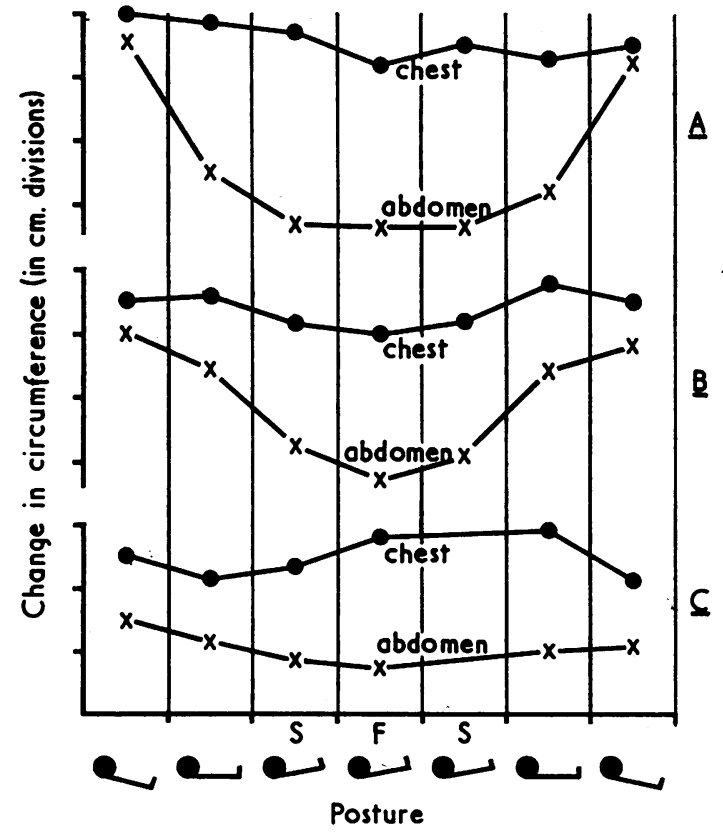

FIG. 4. Changes in circumference of chest and abdomen in moving from one position to another. Measurements made at the resting expiratory level in subjects $A, B$, and $C$. The postures indicated at the bottom of the diagram are, from left to right, 15 degree head-up, horizontal, 15 degree head-down with shoulders supported, 15 degree head-down supported by the feet, etc. 
T A B L E I I I

INCREASE IN CIRCUMFERENCE OF RIB CAGE EXPRESSED AS A PERCENTAGE OF SUM OF INCREASE OF RIB CAGE AND ABDOMEN

\begin{tabular}{|c|c|c|c|c|c|}
\hline \multirow{2}{*}{\multicolumn{2}{|c|}{ Posture }} & & \multicolumn{3}{|c|}{$\begin{array}{l}\text { Rib Cage, Percentage of } \\
\text { Total Increase }\end{array}$} \\
\hline & & & Subject A & Subject B & Subject C \\
\hline $\begin{array}{l}\text { Standing } \quad . \\
\text { Sitting } . \\
\text { 15 degrees feet-down : } \\
\text { Horizontal, supine } \\
\text { 15 degrees head-down }\end{array}$ & $\begin{array}{l}\ddot{ } \\
\cdots \\
\cdots\end{array}$ & $\begin{array}{l}\cdots \\
\cdots \\
\cdots\end{array}$ & $\begin{array}{l}56 \\
70 \\
32 \\
26 \\
37\end{array}$ & $\begin{array}{l}27 \\
42 \\
30 \\
26 \\
23\end{array}$ & $\begin{array}{l}62 \\
47 \\
37 \\
41 \\
59\end{array}$ \\
\hline
\end{tabular}

chest movement in the head-down than in the sitting or horizontal positions, and this may be related to the lower oxygen cost of breathing which was found in the head-down position.

\section{DISCUSSION}

Clinical experience has shown that in ill patients, particularly after heart operations, the energy required for breathing may place too great a strain on the circulation, and reduction of the energy expenditure by intermittent positive pressure respiration may be necessary for survival of the patient. Other patients whose cardiorespiratory systems are less severely restricted may nevertheless be handicapped by an increase in the oxygen cost of breathing. The oxygen cost of breathing is higher when the patient is lying horizontally than when the patient is in the sitting position, and still higher in the 15 degree head-down position. Owing to the duration of the experiments the measurements in different positions had to be carried out on different days, and although there was some variation in the total oxygen uptake of the body from one day to another, there was no significant difference in the resting oxygen uptake with the body in one position as compared with another.

The increased oxygen uptake when breathing through an added dead space may be partly due to the increased work of the heart. Measurements of heart rate in subject $B$ showed rates of 74,64 , and 59 per minute in the sitting, supine, and 15 degree head-down positions respectively, and the heart rates increased by $11 \%, 9 \%$, and $12 \%$ respectively when breathing through a dead space. The cardiac output does increase with $\mathrm{CO}_{2}$-induced (Fishman, Fritts, and Cournand, 1960) or voluntary hyperventilation (Norlin, 1932) but there is no reason to believe that the increase is any greater in one body position than in another and it is probable that the different oxygen cost of ventilation in the different body postions is due to the oxygen uptake of the respiratory muscles. This increased work of breathing can be considered as follows :

WORK DONE ON THE LUNGS The lung compliance is probably unchanged in moving from the sitting to the supine position (Knowles, Hong, and Rahn, 1959). There are no data on lung compliance in the 15 degree head-down position but measurements of relaxation pressure in this position (see below) suggest that no appreciable increase occurs.

Marcelle and Petit (1963) have shown, by the use of an interrupter technique, that an increase in the non-elastic resistance of the lungs occurs on changing from the sitting to the supine position and this change, which in their subjects was an increase of $27 \%$, could be explained by the shift of the respiratory excursion towards the expiratory position when the subject lay flat. The non-elastic resistance of the lungs in subject $B$, measured by the intra-oesophageal pressure technique, was 1.3 $\mathrm{cm}$. water $/(1 . / \mathrm{sec}$.) in the sitting position, $2 \cdot 2$ in the supine position, 2.9 in the 15 degree head-down position, and 1.8 in the horizontal prone position, An increase in the non-elastic resistance by $27 \%$ above that in the sitting position would increase the work of breathing, at a minute volume of 10 litres per minute, by $0.01 \mathrm{~kg} . \mathrm{m} . / \mathrm{min}$. Assuming an efficiency of the respiratory muscles of $10 \%$ and an oxygen equivalent of $2 \cdot 1 \mathrm{~kg} \cdot \mathrm{m} . / \mathrm{ml}$. oxygen, this would increase the oxygen uptake of the subject by $0.05 \mathrm{ml} . / \mathrm{min}$. The values of nonelastic resistance actually obtained for subject B in the supine position may be falsely high but an increase in non-elastic resistance from 1.3 to $2.0 \mathrm{~cm}$. water $/(1 . / \mathrm{sec}$.) would increase the oxygen consumption, at a minute volume of 10 litres per minute, by only $0.25 \mathrm{ml}$. oxygen $/$ minute, assuming that the efficiency remained at $10 \%$. The measured increase in oxygen uptake at 10 litres per minute was approximately $10 \mathrm{ml} . / \mathrm{min}$. (Fig. 3).

WORK DONE ON THE CHEST WALL The compliance of the chest wall (rib cage and abdomen) as measured by relaxation pressures is greater in the supine position than in the upright position (Agostoni and Mead, 1964), because the vertical distance through which the abdominal contents have to be moved during inspiration is less in the supine position. I think that the vertical distance through which the abdominal contents would have to be moved during inspiration would increase when the subject was tilted 15 degrees head-down and that the compliance would decrease. Measurements on subject $B$ showed no significant difference between the compliance of the lungs and 
chest wall (relaxation pressures) measured in the sitting $(0 \cdot 1481 . / \mathrm{cm}$. water; S.D. 0.015$)$, supine $(0.151 \mathrm{l} / \mathrm{cm}$. water; S.D. 0.015$)$ and 15 degree head-down position $(0.1371 . / \mathrm{cm}$. water; S.D. 0.025 ). The relaxation pressures in the obese subject $A$ were not measured but Naimark and Cherniack (1960) 'found that whereas the chest wall compliance of normal subjects was not changed on lying down the chest wall compliance of obese subjects (mean body weight $107 \mathrm{~kg}$.) was decreased by $23 \%$. Subject A was not as obese as the subjects of Naimark and Cheniack, but it is possible that his chest wall compliance decreased on lying down. Mead (1966) has shown that the compliance of the chest wall measured by relaxation pressures is not necessarily the same as that during respiration. When relaxation pressures are measured at different lung volumes about two-thirds of the volume change occurs in the rib cage and onethird in the abdomen. During normal respiration about three-quarters of the volume change takes place in the abdomen and one-quarter in the rib cage. This deviation from the proportional volume change occurring during relaxation means that the chest wall is not adapting to volume change in the most efficient way and thus the effective compliance of the chest wall is decreased. The proportion of the chest wall movement attributable to the rib cage was usually reduced in the supine and 15 degree head-down positions as compared with the sitting position (Table III). This means that the work done in moving the chest wall would be increased in the supine and 15 degree head-down positions.

MUSCULAR EFFICIENCY OF RESPIRATION It has been suggested, on theoretical grounds, that the efficiency of the diaphragm is less when it is more domed than when it is in a flatter position (Marshall, 1962). In the supine and 15 degree head-down positions in subjects $A$ and $B$, the diaphragm was considerably more domed than in the sitting position and this may have contributed to the reduced efficiency of breathing in the supine and 15 degree head-down positions.

In addition to the increased oxygen cost of breathing in the head-down position, the efficiency of distribution of ventilation and blood flow must also be considered. The physiological dead space of the lungs increases in the upright as compared with the supine position (Larson and Severinghaus, 1962 ; Riley, Permutt, Said, Godfrey, Cheng, Howell, and Shepard, 1959). This would be expected in view of the reduced perfusion of the upper lobes of the lungs in the upright position
(West and Dollery, 1960) but Larson and Severing- $\underset{\vec{\rho}}{\stackrel{\vec{\rho}}{2}}$ haus (1962) were unable to confirm any increase in $?$ alveolar dead space in the seated subject; the whole of the increase in physiological dead space $\frac{\bar{\sigma}}{\bar{\omega}}$ in changing from the supine to the sitting position $\overrightarrow{\vec{D}}$ was due to an increase in anatomical dead space $\varrho$ of about $28 \%$.

The efficiency of gas mixing is reduced in the $\overrightarrow{0}$ supine and head-down positions (Blair and Hickam, 1955 ; Bouhuys and Lennep, 1962) but, $\vec{\omega}$ in spite of this impaired gas mixing, the tidal $\underset{\vec{F}}{\vec{f}}$ volume has often been found to be lower in the $\times$ supine or head-down positions as compared with the sitting position (Christie and Beams, $1922 ; \omega$ Lawrence, Hurxthal and Bock, 1927 ; WoodSmith, Horne, and Nunn, 1961). The arterial $\mathrm{PcO}_{2} \mathrm{O}$ has also been reported to be higher in the supine $\frac{}{5}$ position (Lawrence et al., 1927 ; Riley et al., 1959), $\vec{z}$ although this was not found by Larson and Severinghaus (1962). The subjects in this study showed no difference in the resting ventilation in the three positions, but with the larger of the two added dead spaces the ventilation of subjects $A$ D and $B$ was least in the 15 degree head-down position (Fig. 2).

The clinical implication of these results is that patients with an impaired circulation, in whom it $\stackrel{\mathbb{\Omega}}{\mathscr{Q}}$ is important to keep the cardiac work to a mini- $\overrightarrow{\vec{B}}$ mum, will be using more energy to breathe when $\frac{0}{3}$ lying flat than when sitting and they will use even more energy in the 15 degree head-down position. The cardiac output is also greater in the supine than in the sitting position (Bevegård, Holmgren, $\overline{0}$ and Jonsson, 1960 ; Lawrence et al., 1927). The $\underset{x}{\stackrel{0}{x}}$ requirements for the reduction of respiratory work are thus contrary to those for prevention of stasis 3 . in the leg veins. If a patient is in severe respiratory 8 difficulty and requires tracheostomy and positive $₹$ pressure respiration the disadvantages of a head-o down position are largely removed. Patients who? are less severely incapacitated, and who do noto require assisted respiration, may find that the head-down position increases the work of breath- $\odot$ ing by an intolerable amount. This will apply N particularly to obese patients.

Partial collapse of the lung often occurs aftero operation, and Beecher (1933) found that the functional residual capacity fell to $80 \%$ of the $\frac{C}{\Phi}$ initial value by the fourth day after operation. $\stackrel{\oplus}{?}$ Reduction of the functional residual capacity 0 which occurs in the 15 degree head-down position, 0 particularly in obese patients, will itself lead to $\stackrel{\mathbb{Q}}{\mathbb{Q}}$ partial collapse of the lungs in the same way that reduction of lung volume by chest strapping will $\frac{}{\sigma}$ cause lung collapse (Caro, Butler, and DuBois, 
1960). Lung collapse will result in shunting of blood in the lungs and arterial anoxia.

It is essential that blood is not allowed to stagnate in the leg veins after operation. During the period that the patient is unable to carry out voluntary movements, raising the legs and/or electrical stimulation of the leg muscles may be the only ways of maintaining an adequate rate of blood flow. Elevation of the legs without tilting the whole bed creates problems ; it may require a special bed or special supports under the mattress and a patient in this position is more difficult to nurse than a patient on a flat, tilted bed. Frequent turning of the patient from one side to the other is difficult if the bed is angled in the middle. Once the patient is conscious and strong enough to cooperate, elevation of the legs is not so important and, as Frykholm (1940) pointed out, tilting the bed foot-down may be equally effective in preventing leg vein thrombosis provided that the patient is encouraged to exercise the legs.

\section{REFERENCES}

Agostoni, E., and Mead, J. (1964). Statics of the Respiratory System. In Handbook of Physiology, Section 3: Respiration, Volume 1, Chapter 13, p. 387. American Physiological Society, Washington, D.C.

Beecher, H. K. (1933). Effect of laparotomy on lung volume. Demonstration of a new type of pulmonary collapse. J. clin. Invest., 12, 651.

Bevegård, S., Holmgren, A., and Jonsson, B. (1960). The effect of body position on the circulation at rest and during exercise, with special reference to the influence on the stroke volume. Acta physiol. scand., 49, 279.

Blair, E., and Hickam, J. B. (1955). The effect of change in body position on lung volume and intrapulmonary gas mixing in normal subjects. J. clin. Invest., $34,383$.

Bouhuys, A., and Lennep, H. J. van (1962). Effect of body posture on gas distribution in the lungs. J. appl. Physiol., 17, 38.
Campbell, E. J. M., Westlake, E. K., and Cherniack, R. M. (1959). The oxygen consumption and efficiency of the respiratory muscles of young male subjects. Clin. Sci., 18, 55 .

Caro, C. G., Butler, J., and DuBois, A. B. (1960). Some effects of restriction of chest cage expansion on pulmonary function in man: an experimental study. J. clin. Invest., 39, 573.

Christie, C. D., and Beams, A. J. (1922). The estimation of normal vital capacity with especial reference to the effect of posture. Arch. intern. Med., 30, 34.

Fishman, A. P., Fritts, H. W., and Cournand, A. (1960). Effects of breathing carbon dioxide upon the pulmonary circulation. Circulation, 22, 220.

Fowler, G. R. (1900). Diffuse septic peritonitis, with special reference to a new method of treatment, namely, the elevated head and trunk posture, to facilitate drainage into the pelvis, with a report of 9 consecutive cases of recovery. Med. Rec. (N.Y.), 57, 617.

Frykholm, R. (1940). The pathogenesis and mechanical prophylaxis of venous thrombosis. Surg. Gynec. Obstet., 71, 307.

Knowles, J. H., Hong, S. K., and Rahn, H. (1959). Possible errors using esophageal balloon in determination of pressure-volume characteristics of the lung and thoracic cage. J. appl. Physiol., 14, 525.

Larson, C. P., and Severinghaus, J. W. (1962). Postural variations in dead space and $\mathrm{CO}_{2}$ gradients breathing air and $\mathrm{O}_{2}$. Ibid., 17, 417 .

Lawrence, J. S., Hurxthal, L. M., and Bock, A. V. (1927). Variations in blood flow with changes in position in normal and pathologic subjects. J. clin. Invest., 3,613 .

Marcelle, R., and Petit, J. M. (1963). Influence de la position corporelle sur la résistance pulmonaire. Rev. franç. Étud. clin. biol., 8, 694.

Marshall, R. (1962). Relationships between stimulus and work of breathing at different lung volumes. J. appl. Physiol., 17, 917.

Mead, J. (1966). Mechanical factors in the control of breathingthree problems. In Breathlessness, Proc. int. Symposium, Man chester, 1965, p. 139. Ed. Howell, J. B. L., and Campbell, E. J. M Blackwell, Oxford.

- and Whittenberger, J. L. (1953). Physical properties of human lungs measured during spontaneous respiration. J. appl. Physiol., 5,779 .

Naimark, A., and Cherniack, R. M. (1960). Compliance of the respiratory system and its components in health and obesity. lbid., 15, 377.

Norlin, G. (1932). Circulation and forced respiration in man. Skand. Arch. Physiol., 64, 239.

Riley, R. L., Permutt, S., Said, S., Godfrey, M., Cheng, T. O. Howell, J. B. L., and Shepard, R. H. (1959). Effect of posture on pulmonary dead space in man. J. appl. Physiol., 14, 339.

West, J. B., and Dollery, C. T. (1960). Distribution of blood flow and ventilation-perfusion ratio in the lung, measured with radio-

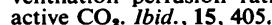

Wood-Smith, F. F., Horne, G. M., and Nunn, J. F. (1961). Effect of posture on ventilation of patients anaesthetised with halothane. Anaesthesia, 16, 340. 